\title{
Exploring Social Learning Analytics to Support Teaching and Learning Decisions in Online Learning Environments
}

\author{
Rogers Kaliisa ${ }^{1[0000-0001-6528-8517]}$, Anders I. Mørch ${ }^{20000-0002-1470-5234]}$ and Anders \\ Kluge 3 [0000-0001-5092-5819] \\ Department of Education, University of Oslo, Norway \\ \{rogers.kaliisa, anders.morch, anders.kluge\}@iped.uio.no
}

\begin{abstract}
Most teachers to date have adopted summative assessment items as a benchmark to measure students' learning and for making pedagogical decisions. However, these may not necessarily provide comprehensive evidence for the actual learning process, particularly in online learning environments due to their failure to monitor students' online learning patterns over time. In this paper, we explore how social learning analytics (SLA) can be used as a proxy by teachers to understand students' learning processes and to support them in making informed pedagogical decisions during the run of a course. This study was conducted in a semester-long undergraduate course, at a large public university in Norway, and made use of data from 4 weekly online discussions delivered through the university learning management system Canvas. First, we used NodeXL a social network analysis tool to analyze and visualize students' online learning processes, and then we used Coh-Metrix, a theoretically grounded, computational linguistic tool to analyze the discourse features of students' discussion posts. Our findings revealed that SLA provides insight and an overview of the students' cognitive and social learning processes in online learning environments. This exploratory study contributes to an improved conceptual understanding of SLA and details some of the methodological implications of an SLA approach to enhance teaching and learning in online learning environments.
\end{abstract}

Keywords: Social Learning Analytics, Teaching and Learning, Online Learning Environments, NodeXL, Coh-Metrix.

\section{Introduction}

Most teachers rely on summative assessments (coarse-grained analysis) such as the end of term examinations, as a benchmark to measure students' learning and to retrospectively make decisions regarding how best to teach their subjects to the next cohort of students $[20,25]$. However, such methods are prone to challenges such as personal bias, and the failure to monitor students' online learning patterns (i.e., course logins, discussions attended, student-student, and student-course artefact interactions) during the run of the course [23], yet this could enable teachers to provide adaptive feedback 
and to adjust teaching strategies. At the same time, teaching and learning are gradually transferred to online environments (LMS, MOOCs, etc.). One way to deal with this challenge is by using more objective and automated methods to evaluate students' online learning in real time and to enable teachers to make timely informed (formative) educational decisions. Drawing on this, this paper suggests social learning analytics (SLA) as a possible approach to explore students' online learning patterns. Specifically, we are interested in exploring students' online interactions/networks and their digital artefacts (i.e. discussion posts) to produce insights into students' participation, and meaningful discourse patterns that could support teaching and learning decisions. As a methodological contribution, we use NodeXL [24] a social network analysis tool to analyze and visualize students' online learning combined with CohMetrix, a theoretically grounded, computational linguistic tool [4] to analyze the discourse features of students' discussion posts. Consequently, we gained insight and a richer understanding of the students' social and cognitive learning processes. In the following sections, we provide a brief overview of SLA situated within the context of the social learning perspective, highlight the research questions, describe the research methodology, present findings, and discuss research, limitations and suggestions for future research.

\section{Background}

\subsection{Social Perspectives of Learning}

Theoretical and empirical evidence in the learning sciences view learning as a social process that cannot be only accounted for by cognition and behaviors of the individual [7]. This is arguably, why teachers and researchers have increasingly applied pedagogical approaches such as interactive representations associated with socioconstructivist principles [16]. According to the socio-cultural perspectives, learning is an aspect of self-organization of both the human organism and the ecosocial system in which individual functions as a human being $[17,22]$. This implies that learning is defined through interaction with others and mediated by artefacts, technology and semiotic tools such as language $[13,17]$. Indeed, the joint interaction between individuals forms a basis for mastery of useful strategies, skills, concepts and knowledge [13]. Online learning environments where students and teacher interactions are usually mediated by technological tools [11], offer a new context in which to explore key aspects of learning from a sociocultural perspective. For example, more recently, the increase in computer-mediated learning has created new conditions for teaching and learning [22], through tools such as wikis, and online discussion forums. These produce a gold mine of data that social learning analytics techniques can utilize to explore and identify pedagogically valuable social, cognitive and affective features related to students' social learning processes [4]. 


\subsection{Social Learning Analytics (SLA)}

SLA is a subset of learning analytics, which is concerned with the collection, measurement and analysis of students' digital artefacts and online interactions in order to understand their activities, social behaviours, and knowledge creation in a social learning setting $[7,15]$. SLA draws on the significant educational research work evidencing that new skills and ideas are developed and passed on through interactions and collaboration, and that learning cannot be understood without reference to context [13]. Ferguson and Shum (2012) identified five categories of SLA under the umbrella of inherent social analytics and socialized analytics. The inherent ones include; social network analytics (SNA) and discourse analytics (DA), while the socialized ones include; content analytics (CA); disposition analytics (DA), and context analytics (CA). In this current study, we explore how the analysis of students' online interactions and discourse can provide insights into the students' learning processes. Therefore, social network analytics and discourse analytics which are regarded as inherently social are the focus of this study. In this paper, we use SLA as an umbrella concept combining social network analytics (SNA) and discourse analytics (DA).

\subsection{Social Network Analytics (SNA)}

Social network analytics (SNA) is derived from the concept of social network analysis which studies and analyses social ties, relations, roles and network formations [3]. The principles of social network analysis derive from graph theory, which looks at patterns of relational connections between nodes in a graph. The nodes in a social network graph are the actors, who can be individuals or collective units such as teams or organizations [11]. In learning and education settings, the actors may be students connected to each other within a class or learning activity; or teachers and students in a class. Based on the principles of social network analysis, social network analytics aims at interpreting the individual and group interactions and how these support learning. An example is Hernandez-Garcia and colleagues (2015) who applied social network analytics to examine the relation between social network analysis parameters and student outcomes. The study showed that social network analytics can highlight the visible and invisible interactions occurring in online environments, thus helping to improve the learning process based on the information about the actors and their activity in the online learning environment.

\subsection{Discourse Analytics (DA)}

The social ties and relations occurring in social learning environments are strengthened through dialogue between students and teachers [8]. DA involves the analysis of the large amounts of text generated during the online interactions [7]. Previous research has reported that educational success is related to the quality of learners' educational dialogue [9], which can be measured through discourse analysis. This implies that DA can be used to analyze large amounts of educational text, and potentially provide insights into the quality of students' text and speech posted in online envi- 
ronments. For example, Dowell and colleagues (2015) combined language and discourse as a tool to explore the association between students' traditional academic performance and social centrality in a MOOC environment. The findings revealed that students who engaged in a more expository style of discourse performed better while those that used a more narrative style of discourse gained a more central position in their social network. More recently, Joksimovic et al (2018) used discourse analysis to examine the association between social capital, linguistic and discourse patterns. The findings showed that learners with more connections had a linguistic profile that is more narrative with lower referential cohesion and more complex syntax.

\section{Identified Gaps and Research Questions}

The application of social network analysis to educational contexts in this study is not novel, but our preliminary literature review shows that there is no sufficient empirical evidence for the use of SLA to identify and generate insights to teachers, in order to support informed learning and teaching decisions. More importantly, most of the previous studies are limited to the description of social networks, without analysis of the discourse dimensions of these interactions. However, the combination of social network and discourse analysis of students' artefacts could allow for a more nuanced description of student engagement and learning [1, 21], and necessary to reach an overall interpretation of such complex dynamics generated among students [10]. From this background, this study aims to explore the potential of SLA (i.e. social network analytics and discourse analytics), as a way to understand the underlying learning processes within online learning environments. Towards this goal, we address the following research question: What are the opportunities of SLA in terms of generating relevant insights about students' online learning processes which teachers can use to make timely and informed pedagogical decisions?

\section{Methodology}

\subsection{Context and Participants}

This study employed a mixed methods approach, by combining social network and discourse analysis to analyze and visualize students' online learning processes [8]. We extracted and analyzed data from the discussion forum contributions posted on Canvas, a learning management system, within a blended bachelors course (i.e. involving face to face and online activities) at a public university in Norway. This course is taught as a part of the university's bachelor in pedagogy. The main course objective was to introduce selected learning technologies and applications and to familiarize students with the central theoretical perspectives and studies of learning technologies. The course had a total number of 34 students and four teachers. To ensure active use of the online discussions, in parallel to the face to face classroom; all students had to participate in a weekly online discussion forum that ran for 7 weeks in 
the period of January 2019 to April 2019. The discussions were conducted asynchronously, and all subsequent messages in the thread were text-only. Participation in the discussion was compulsory with each student expected to make two contributions and respond to at least one other student every week. For each week, teachers created a new discussion thread based on the topic of the next lecture. Thereafter, students posted their contributions in response to the main discussion question or responding to posts by other students.

\subsection{Data Preparation and Analyses}

Prior to the analysis, the students' network and linguistic/discourse data were extracted, cleaned and categorized by week, to provide a benchmark for further analysis and identification of relevant patterns. In order to generate initial insights and relevant hypotheses, this study focuses on interaction and discourse on discussion posts published during the first four weeks of the course. Students' network and discourse data was extracted and analyzed using two methods. First, social network analysis to identify significant interaction patterns among students, and secondly, discourse analysis to identify significant linguistic/discourse features connected to the students' contributions. Individual students were the unit of analysis.

\section{Social Network Analysis}

To perform social network analysis, we re-constructed social network relationships based on student-student, student-teacher, and teacher-student interactions. Although the Canvas LMS has in-built Canvas analytics, there is currently no plug-in that supports the automatic mining of discussion forum data directly from the platform. Thus, the first author manually extracted students' interaction data from Canvas into NodeXL (version 1.0.1.410) a third-party social network tool [24]. Specifically, the coding process in NodeXL included all students and teachers who posted in the discussion forum. For example, if student S4 posted a message in response to the main discussion question (DQ), we coded this as (S4>DQ), then if student S10 posted a message in response to S4's initial thread message, we coded this as (S10>S4). Thus, the analyzed ties represent unweighted and undirected graphs which were constructed to represent the students' interactions on the Canvas platform. After the coding, we used the social network analysis measures suggested in previous studies [1] (i.e. degrees, closeness, and betweenness) to assess and determine the level of importance, strength, and influence each node/student had on the broader social network [2]. The degree centrality measure is used to determine the number of ties an individual student has with other actors in the network [2]. Closeness centrality indicates the degree of relationships an actor has formed with the entire network, while betweenness centrality refers to the extent to which an actor occurs within the shortest path between other nodes, thus facilitating the spread of information within the network [3]. 


\section{Discourse Analysis}

In this study, we analyzed the content of students' contributions in order to extract significant discourse patterns. This analysis was performed using Coh-Metrix (version 3.0 ), which is an automated textual assessment tool $[4,19]$, and used in previous studies [19]. Coh-Metrix is a computational linguistics facility that analyzes higher-level features of language and discourse [19]. In this study, the following five principal components of Coh-Metrix were calculated. (1) Narrativity. That is the extent to which the text is in the narrative genre, which conveys a story, a procedure, or a sequence of episodes of actions and events with animate beings (2) Deep cohesion. The extent to which the ideas in the text are cohesively connected at a deeper conceptual level that signifies causality or intentionality, (3) Referential cohesion. The extent to which explicit words and ideas in the text are connected with each other as the text unfolds, (4) Syntactic simplicity. Which reflects the degree to which the sentences in the text contain fewer words and use simpler, familiar syntactic structures, and (5) Word concreteness. The extent to which content words are concrete, meaningful, and evoke mental images as opposed to abstract words [19].

\section{$5 \quad$ Findings and Discussion}

\subsection{Social Network Findings}

First, we analyzed students' interactions in the online discussion forum as illustrated in socio-grams Figs. 1-4, with each figure representing a weekly discussion forum.
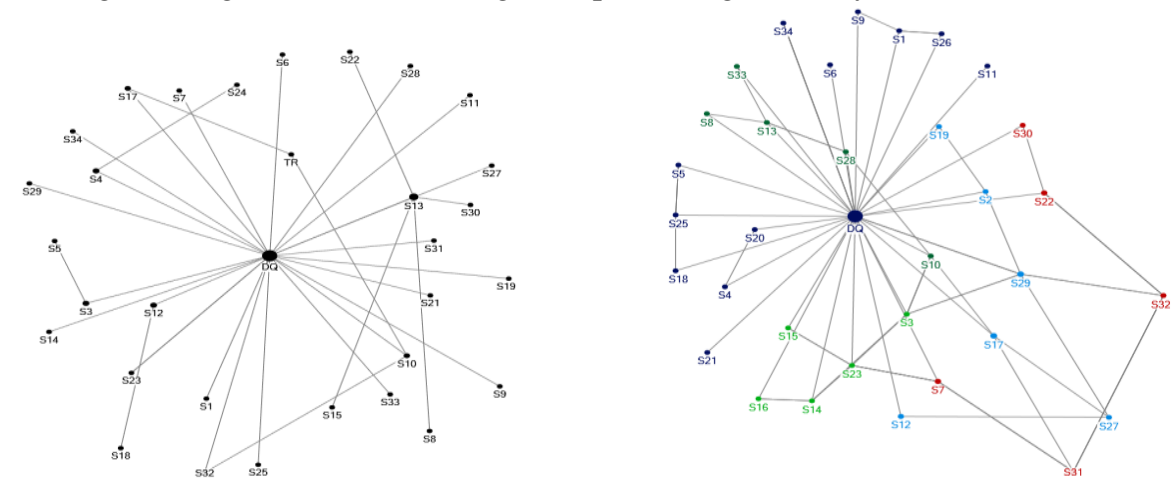

Fig. 1. Sociogram of week one discussions. Fig. 2. Sociogram of week two discussions. 

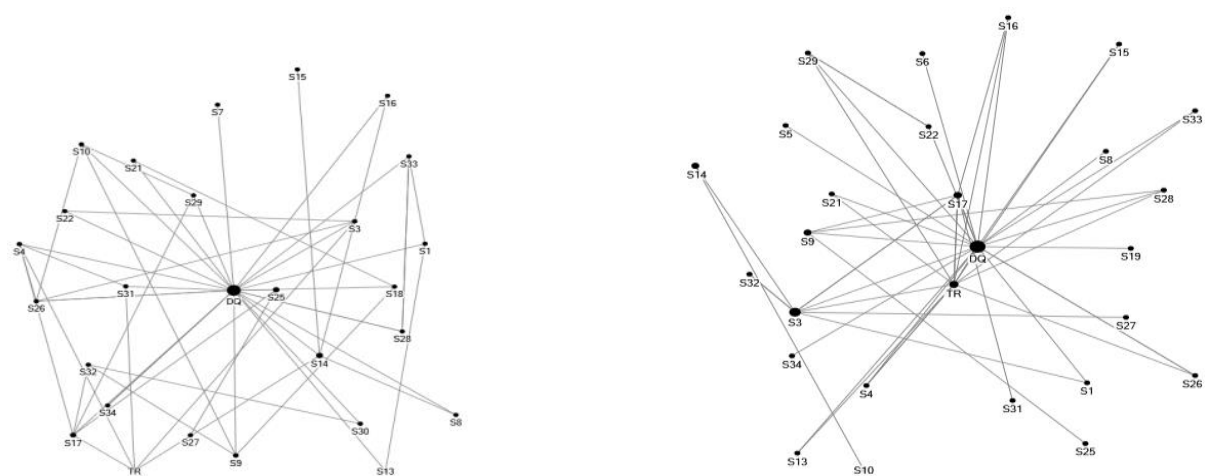

Fig. 3. Sociogram of week three discussions. Fig. 4. Sociogram of week four discussions

The social network visualizations (Figs.1-4) provide an aggregate visual representation of the social structure connecting 34 students and 4 teachers during the 4 weeks of online discussion activities. Despite the fact that student names have been removed for confidentiality purposes, the labels demonstrate the position of each student within the network in a given week. Consequently, in these figures, the size and location of the nodes correspond to their degree centrality or the number of edges in the network. This means that the bigger a node is, the more messages the student/teacher represented by that node sent and received. Similarly, the more central a node is to the center or main discussion question (DQ) the more powerful it is. Thus, these networks can be used to identify students and teachers that were highly/less engaged in the discussion network. For example, Fig. 1 clearly illustrates a less engagement and interaction among students, with most of the communication directed to the original discussion question here coded as (DQ). However, improved interactions are observed in Figs. 2-4 with students and teachers interacting more than in week one. For example in Figure 4, the average degree centrality increased, which is seen by enlarged node sizes (e.g. S3, S17, and S9).

In addition, detailed analysis detected interesting patterns with some students having more activity and standing out across the 4 weeks. For example, in week 1, S13 was the most active with a betweenness centrality of 114 . In week 2 , S29 had a betweenness centrality of 27.4, and in week 3, S14 scored a high betweenness centrality of 29.7. In week 4, S3 had the highest betweenness centrality of 94.7. Similarly, the figures also indicate some disconnected/less-active students. For example, S18 in week 1 and 2 with a betweenness centrality of 0.0 , while S34 and S25 both have a betweenness value of 0.0 in week 3 and 4 respectively. More importantly, the active involvement of teachers in week 3 and 4 as illustrated in Figs. 3 and 4 had an impact on the frequency of some students' posting. For example, a deeper analysis showed that S3 and S17, who were associated with the strongest brokerage role across the 4 weeks, recorded the highest degree centrality in week 3 and 4 . This is partly attributed to the teachers' involvement as witnessed in the number of interactions these two students had with the teachers in both weeks. 


\subsection{Discourse Findings}

Next, we performed automated discourse analysis for the 4 weeks discussion content using Coh-Metrix. We used social network analysis data presented in the previous section to "zoom in" on the most active and less active students for subsequent discourse analysis. Tables 1 and 2 illustrate social network analysis and discourse analysis values for the 10 selected students in week 1 and 2 .

Table 1. Week 1 discourse and SNA metrics results

\begin{tabular}{|c|c|c|c|c|c|c|c|c|c|c|}
\hline & \multicolumn{5}{|c|}{ Active Students } & \multicolumn{5}{|c|}{ Less Active Students } \\
\hline SNA & S13 & S3 & S4 & $\mathrm{S} 12$ & S10 & S5 & S18 & S24 & S8 & S11 \\
\hline Degree & 5 & 2 & 2 & 2 & 3 & 1 & 1 & 1 & 1 & 1 \\
\hline $\begin{array}{l}\text { Between- } \\
\text { ness }\end{array}$ & 114 & 30 & 30 & 30 & 15 & 0.0 & 0.0 & 0.0 & 0.0 & 0.0 \\
\hline Closeness & $\begin{array}{l}0.01 \\
6\end{array}$ & $\begin{array}{l}0.01 \\
5\end{array}$ & $\begin{array}{l}0.01 \\
5\end{array}$ & $\begin{array}{l}0.01 \\
5\end{array}$ & $\begin{array}{l}0.01 \\
5\end{array}$ & $\begin{array}{l}0.01 \\
0\end{array}$ & $\begin{array}{l}0.01 \\
0\end{array}$ & $\begin{array}{l}0.01 \\
0\end{array}$ & $\begin{array}{l}0.01 \\
1\end{array}$ & $\begin{array}{l}0.01 \\
4\end{array}$ \\
\hline & \multicolumn{10}{|c|}{ Discourse Analysis Results } \\
\hline $\begin{array}{ll}\text { No } & \text { of } \\
\text { words } & \end{array}$ & 264 & 212 & $\begin{array}{l}100 \\
6\end{array}$ & 133 & 373 & 100 & 204 & 114 & 121 & 206 \\
\hline Narrativity & 73 & 73 & 47 & 68 & 53 & 94 & 37 & 64 & 74 & 64 \\
\hline $\begin{array}{l}\text { Deep } \\
\text { Cohesion }\end{array}$ & 69 & 48 & 37 & 94 & 99 & 10 & 55 & 32 & 23 & 62 \\
\hline $\begin{array}{l}\text { Referential } \\
\text { Cohesion }\end{array}$ & 67 & 43 & 62 & 35 & 46 & 83 & 15 & 31 & 70 & 25 \\
\hline $\begin{array}{l}\text { Syntax } \\
\text { Simplicity }\end{array}$ & 41 & 19 & 62 & 49 & 25 & 6 & 68 & 17 & 19 & 50 \\
\hline $\begin{array}{l}\text { Word } \\
\text { Concrete- } \\
\text { ness }\end{array}$ & 4 & 41 & 18 & 5 & 13 & 13 & 10 & 10 & 17 & 42 \\
\hline
\end{tabular}


Table 2. Week 2 discourse and SNA metrics results

\begin{tabular}{|l|r|r|r|r|r|r|r|r|r|r|}
\hline & \multicolumn{9}{|c|}{ Active Students } & \multicolumn{6}{|c|}{ Less Active Students } \\
\hline SNA & S29 & S17 & S7 & S22 & S3 & S6 & S11 & S21 & S34 & S18 \\
\hline Degree & 5 & 4 & 3 & 3 & 5 & 1 & 1 & 1 & 1 & 2 \\
\hline $\begin{array}{l}\text { Between- } \\
\text { ness }\end{array}$ & 27.4 & 23.6 & 13.3 & 12.3 & 4.4 & 0.0 & 0.0 & 0.0 & 0.0 & 0.0 \\
\hline Closeness & $\begin{array}{c}0.01 \\
6\end{array}$ & $\begin{array}{c}0.01 \\
6\end{array}$ & $\begin{array}{c}0.01 \\
6\end{array}$ & $\begin{array}{c}0.01 \\
6\end{array}$ & $\begin{array}{c}0.01 \\
6\end{array}$ & $\begin{array}{c}0.01 \\
5\end{array}$ & $\begin{array}{c}0.01 \\
5\end{array}$ & $\begin{array}{c}0.01 \\
5\end{array}$ & $\begin{array}{c}0.01 \\
5\end{array}$ & $\begin{array}{c}0.01 \\
5\end{array}$ \\
\hline & \multicolumn{8}{|c|}{ Discourse Analysis Results } \\
\hline $\begin{array}{l}\text { No of } \\
\text { words }\end{array}$ & 522 & 505 & 337 & $\begin{array}{c}127 \\
3\end{array}$ & 402 & 158 & 110 & 225 & 457 & 820 \\
\hline Narrativity & 57 & 85 & 29 & 61 & 75 & 82 & 95 & 79 & 41 & 40 \\
\hline $\begin{array}{l}\text { Deep } \\
\text { Cohesion }\end{array}$ & 97 & 96 & 98 & 64 & 93 & 11 & 30 & 44 & 85 & 45 \\
\hline $\begin{array}{l}\text { Referential } \\
\text { Cohesion }\end{array}$ & 7 & 51 & 24 & 64 & 77 & 40 & 28 & 45 & 80 & 24 \\
\hline $\begin{array}{l}\text { Syntax } \\
\text { Simplicity }\end{array}$ & 71 & 73 & 89 & 57 & 9 & 20 & 35 & 17 & 23 & 57 \\
\hline $\begin{array}{l}\text { Word } \\
\begin{array}{l}\text { Concrete- } \\
\text { ness }\end{array}\end{array}$ & 1.8 & 6 & 43 & 9 & 58 & 50 & 5 & 40 & 28 & 65 \\
\hline
\end{tabular}

Tables 1 and 2 present an analysis of the discourse features of students' discussion contributions for students with high centrality measures and those with low centrality/peripherally located in the network. In week one (see Table 1), the results suggest that the students who had high centrality measures exhibit different discourse/linguistic features than the students with low centrality measures. For example, S13 who had the biggest degree, betweenness and closeness centrality values was associated with high narrativity (73), deep cohesion (69) and referential cohesion (67). Conversely, S18 who had the lowest SNA scores was associated with higher syntactic simplicity and word concreteness. Similarly, in week 2 (see Table 2), S29 who was better positioned within the network of learners, had a narrativity score of (57), deep cohesion (97), referential cohesion (7), syntax simplicity of (71) and word concreteness of (1.8). On the other hand, S34 with low SNA values had a high referential cohesion (80), and word concreteness of (28). This finding means that the text for less active students contained words and ideas that overlap across sentences and the entire text, while the higher word concreteness means the text was less abstract and meaningful [4].

In addition, an interesting observation from a combined analysis of students' network and discourse patterns revealed an overall change in the linguistic profile of all students (those with high and low centrality values), towards week 3 and 4, which was identified by a higher deep cohesion. This finding suggests that students moved from less narrative/informal discourse styles to a more formal discourse. In practice, the identification of such discourse patterns may help teachers to monitor and detect the quality of the discussions in line with course/task expectations, and to provide personalized support based on students' discourse features. 


\section{General Discussion and Conclusion}

This paper explored the possibility of using social learning analytics (SLA) as a proxy by teachers to understand students' online learning processes and to support them in making informed pedagogical decisions. First, we adopted a social network analysis approach to identify the interactions between students and teachers across the 4 weeks of online discussion. The analysis showed that some students (i.e., S13, S3, S29, and S14) were very active across the 4 weeks hence being regarded as information brokers or bridge builders $[1,8]$. Moreover, some weeks recorded more interactions than others (i.e., week 2, 3 and 4). While a deeper analysis of the nature of the content discussed in each week was not done, the differences in students' interactions and networks across the 4 weeks could be attributed to some elements of course structure in the different weeks [9] as well as the involvement of the teachers in week 3 and 4. This finding confirms previous research that teachers' role and level of participation could affect the level of online discussions [8]. In practice, as noted by Macfadyen and Dawson (2010), these findings reveal that social network analytics can afford insight into students' social learning processes, which teachers can use to identify deviations between the observed and intended interactions [18]. Moreover, in blended learning environments like the one presented in this study, teachers can be alerted about the students to keep an eye on during the face-to-face interactions, and at the same time learn about the direction in which they need to moderate online discussions [8]. This study affirms that the analysis of online social networks can support the collection of pedagogically meaningful information such as, how a student has engaged in a task. This provides teachers with a richer understanding of students' social learning processes in online learning environments, thus providing them with a basis to make informed pedagogical decisions and the creation of more effective learning environments.

Further, discourse analysis results demonstrated that the deep exploration of students' online text can reveal the quality and type of contributions made by students. In other words, even though social networks do not necessarily show evidence of knowledge construction among students, this process can be monitored through discourse analysis, thus gaining a richer understanding of students' cognitive learning processes. For example, a detailed discourse analysis of students' texts across the 4 weeks revealed that students with higher centrality values were associated with higher deep cohesion and syntax simplicity. This suggests that their texts use a more formal style of discourse, put in more effort and engage in increased elaboration [19]. This finding is consistent with previous research, which reported that high performing learners are characterized by a formal discourse [5].

In contrast, students with low centrality values had a more narrative style, which implies a more informal, and story-like style of discourse [19]. Moreover, some students' linguistic profiles changed over time (i.e. from a narrative style to more deep cohesion). Such a finding means that teachers could monitor the progress of students' learning overtime based on the linguistic profile and level of cognitive presence in each post [6] since these are important dimensions for students' learning. By doing so, 
the teacher can evaluate the effectiveness of the learning design, and suggest appropriate strategies to adapt the teaching and learning process. In other words, the linguistic profiles of students' posts could indicate that the discussion forum is not being used according to pedagogical intent, thus, suggesting the teacher to intervene to keep the learning process on track. More importantly, these discourse features have strong implications for understanding students' learning, since constructivist theories imply that comprehension is an important feature to measure students' learning [13, 16].

Overall, the analysis of students' contributions and online interactions reveal that combining social network analytics and discourse analytics can provide quick and useful insights for understanding both the cognitive and social characteristics of students' learning processes which in turn can be used to support teachers in making informed and timely decisions to improve the teaching and students' learning processes (e.g., encouraging less central but involved students to extend their network). This finding supports the claims of many in the technology enhanced learning community that it is important to understand what students are doing and talking about, how they are interacting with the course material, and where comprehension problems arise [26] besides examining who is talking to whom, in order to evaluate the quality of collaborative online learning activities [8]. However, we argue that if teachers and researchers are to benefit from the results coming out of social network and discourse analytics, they should have a clear understanding of the course context and be provided with simple analytics tools/training for meaningful interpretations.

In summary, this exploratory study makes methodological and conceptual contributions to SLA and technology-enhanced learning research. The study demonstrates how teachers and researchers can utilize students' data from online collaborative learning activities, to identify the cognitive and social characteristics of students' learning, using an innovative methodology of combining analysis of social networks and discourse using automated tools like Coh-Metrix. If teachers and researchers identify cognitive/learning features that are directly reflected in students' online activities, there is a great potential to intervene while a course is being taught, an approach to assessment which is difficult to achieve through the more typical surveys and end of term assessments.

\section{Limitations and Suggestions for Future Research}

There are a number of limitations that affect the generalizability and interpretation of the findings of this exploratory study. First, the conclusions of the study are limited by its focus on data collected from a single course, and with a sample size of only 34 students. We also recognize that the analyzed data is based on students' activity of only 4 weeks which could limit a comprehensive view of the students' learning process during this course. Moreover, the discourse analysis we conducted is of exploratory nature aiming at generating theoretical linkages/hypotheses rather than testing hypotheses. These limitations necessitate the need for further studies with welldeveloped hypotheses, analyzing longer durations of students' learning, and with larger samples to validate these initial findings. Nonetheless, despite these limitations, 
this exploratory paper contributes to methodological and conceptual implications for the use of SLA in blended learning environments, and provides a strong foundation for future rigorous research on the sub-field of SLA.

\section{Acknowledgements}

We wish to thank the members of the LiDA Research Group at the Department of Education, the University of Oslo for the constructive feedback on the primary data that informed this article. Special thanks go to Emily Oswald (University of Oslo) for useful comments on a previous version of the article. We thank the anonymous reviewers for their valuable comments on our manuscript. The first author received financial support by a PhD fellowship from the Faculty of Educational Sciences, University of Oslo.

\section{References}

1. Andersen, R., \& Mørch, A. I. (2016). Mutual development in mass collaboration: Identifying interaction patterns in customer-initiated software product development. Computers in Human Behavior, 65, 77-91.

2. Dawson, S., Bakharia, A., \& Heathcote, E. (2010). SNAPP: Realising the affordances of real-time SNA within networked learning environments.

3. De Nooy, W., Mrvar, A., \& Batagelj, V. (2018). Exploratory social network analysis with Pajek: Revised and expanded edition for updated software (Vol. 46): Cambridge University Press.

4. Dowell, N. M., Graesser, A. C., \& Cai, Z. (2016). Language and discourse analysis with Coh-Metrix: Applications from educational material to learning environments at scale. 3(3), 72-95.

5. Dowell, N. M., Skrypnyk, O., Joksimovic, S., Graesser, A. C., Dawson, S., Gasevic, D., Kovanovic, V. (2015). Modeling Learners' Social Centrality and Performance through Language and Discourse. Proceedings of the 8th International Conference on Educational Data Mining.

6. Farrow, E., Moore, J., \& Gašević, D. (2019). Analysing discussion forum data: a replication study avoiding data contamination. Paper presented at the Proceedings of the 9th International Conference on Learning Analytics \& Knowledge.

7. Ferguson, R., \& Shum, S. B. (2012). Social learning analytics: five approaches. Paper presented at the Proceedings of the 2nd international conference on learning analytics and knowledge.

8. Gasevic, D., Joksimovic, S., Eagan, B. R., \& Shaffer, D. W. (2019). SENS: Network analytics to combine social and cognitive perspectives of collaborative learning. Computers in Human Behavior, 92, 562-577. doi:10.1016/j.chb.2018.07.003

9. Gilbert, P. K., \& Dabbagh, N. (2005). How to structure online discussions for meaningful discourse: A case study. British Journal of Educational Technology, 36(1), 5-18.

10. Haya, P. A., Daems, O., Malzahn, N., Castellanos, J., \& Hoppe, H. U. (2015). Analysing content and patterns of interaction for improving the learning design of networked learning environments. British Journal of Educational Technology, 46(2), 300-316. doi:10.1111/bjet.12264 
11. Haythornthwaite, C., \& De Laat, M. (2012). Social network informed design for learning with educational technology. In Informed design of educational technologies in higher education: Enhanced learning and teaching (pp. 352-374): IGI Global.

12. Hernández-García, Á., González-González, I., Jiménez-Zarco, A. I., \& ChaparroPeláez, J. (2015). Applying social learning analytics to message boards in online distance learning: A case study. Computers in Human Behavior, 47, 68-80.

13. John-Steiner, V., \& Mahn. (1996). Sociocultural approaches to learning and development: A Vygotskian framework. Educational psychologist, 31(3-4), 191-206.

14. Joksimović, S., Dowell, N., Poquet, O., Kovanović, V., Gašević, D., Dawson, S., \& Graesser, A. C. (2018). Exploring development of social capital in a CMOOC through language and discourse. The Internet and Higher Education, 36, 54-64.

15. Kent, C., \& Rechavi, A. (2018). Deconstructing online social learning: network analysis of the creation, consumption and organization types of interactions. In (pp. 1-22): Routledge.

16. Kluge, A. (2019). Learning science with an interactive simulator: negotiating the practice-theory barrier. International Journal of Science Education, 1-25.

17. Lemke, J. L. (1997). Cognition, context, and learning: A social semiotic perspective. 37-56.

18. Macfadyen, L. P., \& Dawson, S. (2010). Mining LMS data to develop an "early warning system" for educators: A proof of concept. 54(2), 588-599.

19. McNamara, D. S., Graesser, A. C., McCarthy, P. M., \& Cai, Z. (2014). Automated evaluation of text and discourse with Coh-Metrix: Cambridge University Press..

20. Persico, D., \& Pozzi, F. (2015). Informing learning design with learning analytics to improve teacher inquiry. British Journal of Educational Technology, 46(2), 230-248.

21. Rabbany, R., Elatia, S., Takaffoli, M., \& Zaïane, O. R. (2014). Collaborative learning of students in online discussion forums: A social network analysis perspective. In Educational data mining (pp. 441-466): Springer.

22. Rasmussen, I., \& Ludvigsen, S. (2010). Learning with computer tools and environments: A sociocultural perspective. International handbook of psychology in education, 399-433.

23. Rienties, B., Cross, S., \& Zdrahal, Z. (2017). Implementing a learning analytics intervention and evaluation framework: What works? In Big data and learning analytics in higher education (pp. 147-166): Springer.

24. Smith, M. A., Shneiderman, B., Milic-Frayling, N., Mendes Rodrigues, E., Barash, V., Dunne, C.,Gleave, E. (2009). Analyzing (social media) networks with NodeXL. Paper presented at the Proceedings of the fourth international conference on Communities and technologies.

25. Schmitz, M., Van Limbeek, E., Greller, W., Sloep, P., \& Drachsler, H. (2017, September). Opportunities and challenges in using learning analytics in learning design. In European Conference on Technology Enhanced Learning (pp. 209-223). Springer, Cham.

26. Scheffel, M., Niemann, K., Leony, D., Pardo, A., Schmitz, H. C., Wolpers, M., \& Kloos, C. D. (2012, September). Key action extraction for learning analytics. In European Conference on Technology Enhanced Learning (pp. 320-333). Springer, Berlin, Heidelberg. 